\title{
Navigating adversity: Uncovering the Internationally Educated Nurses' Personal Resilience
}

\author{
Ndolo Njie-Mokonya* \\ The Ottawa Hospital, Canada \\ Submission: January 16, 2018 ; Published: February 08, 2018 \\ *Corresponding author: Ndolo Njie-Mokonya, The Ottawa Hospital, Canada, Email: nnjie@toh.ca
}

\section{Background}

Over the past decade, nursing shortages resulting from factors such as an aging nurse population, early retirement, and fewer graduating nurses [1-3] has led to increased recruitment of internationally educated nurses from both developed and underdeveloped nations. Even though IENs are a valuable addition to the nursing workforce [4], they face a number of challenges at their workplaces [5-7]. Understanding factors surrounding these experiences, particularly how IENs cope in new work environments, is necessary in order to promote skill acquisition and utilization, and foster a positive work environment and resilience during transition. Jackson et al. [8] describe resilience as an active process involving an individual's ability to "adjust to adversity, maintain equilibrium, retain some sense of control over their environment, and continue to move on in a positive manner" (p. 3). Authors suggest nurses who face workplace adversity and other challenges are likely to experience stress may result in them leaving the nursing profession, while other, who remain, are able to face these unpleasant conditions partly due to personal resilience. However, a fuller examination of resilience amongst the IEN group has been unexplored.

This paper presents the findings of a study that examined the transition experiences of IENs during the first five years of practice as registered nurses in Canada's capital city of Ottawa, and centers on the recurring theme of resilience as a resource to facilitate transition. Descriptive phenomenology, founded by Husserl [9], guided the research design and process of this study. Ethical approval was obtained from the University of Ottawa research ethics board (file number: H11-12-09). Recruitment was initiated by purposeful sampling and facilitated through snowball sampling technique [10]. Data collection was accomplished through semistructured interviews; notes from follow-up discussion during data analysis and validation; and, a personal research journal. Data saturation occurred following the interviewing of eleven participants and bracketing was maintained throughout the research.

\section{Findings}

The majority of IENs felt some of their Canadian colleagues routinely questioned their knowledge and competence as RNs. How IENs established credibility with their peers will be described within these subthemes:

\section{Acceptance by colleagues, patients and hospital staff...} "I feel I am not left alone"

This sub-theme refers to IENs' beliefs of being accepted by their nurse colleagues, patients, or family members which, in turn, either facilitated or hindered their transition experience. One participant recalled: You learn a lot from mistakes, and from the mentorship of more experienced nurses and their clinical judgment... My nursing colleagues are receptive, and I feel I am not left alone. Similarly, one IEN explained that her encounters with nursing colleagues at her workplace contributed positively for the most part to her integration experience: Operating room nursing is not direct patient care like on floors...you deal with colleagues more. Some words are hard to pronounce, I have a hard time spelling some drugs. The nurses help me. In contrast, another IEN attributed non-receptive attitudes by nurses trained in Canada to an ignorance of how to work with others, suggesting that "Make the environment conducive...Teach the nurses how to work with other people, they need to put themselves in other people's shoes."

\section{Incivility... "I did not receive help from other nurses"}

While majority of the IENs in this study felt supported by their non-IEN colleagues and patients, they also recounted some unwelcoming encounters with some of their nursing colleagues or members from other disciplinary teams, like physicians. An IEN explains: "Sometimes [some surgeons] are mean to me.... They will ask, 'Are you Canadian? I think the hospitals should hire Canadians first'. I need to learn to speak up more." Another IEN stated, "Some surgeons or anesthetists if they don't like you, they treat you badly...They don't talk, so this hinders communication." 


\section{Proving one's self... "I had to prove myself"}

The way IENs' encountered and dealt with negative staff attitudes seemed to vary, but they all seemed to develop a resilient attitude to these unpleasant attitudes, one that forced them to focus and re-direct their efforts at performing better at their jobs. One IEN stated: Everyone has their territorial thing; before [the Canadian trained nurses] thought I didn't know what to do because I came from another country. I had to prove myself when you shouldn't because the college has assessed everything. Now they're a lot more open than before once they see you know what you are doing they'll come around after you prove yourself This IEN noted that the unwelcoming gestures of her Canadian colleagues made her want to change who she was and to take up the "Canadian way" of expression. She recalled: we are less expressive culturally, here nurses expect more in terms of expression; just trying to change and adapt because we are working here now; knowingly or unknowingly we are learning to adapt.... (But) their attitudes change once they see your experience and knowledge. Resilience was manifested over time in the IENs' unrelenting attempts to prove their capability to provide patient care in a Canadian context. As one IEN stated, "Now they're a lot more open than before once they see you know what you are doing they'll come around after you prove yourself."

To conclude, recognizing and developing innovative ways of leveraging and nurturing resilience among IENs during the early years of their transition is vital and requires the involvement of all stakeholders in order to foster the development of effective coping skills and personal resilience strategies. This is likely to improve nursing practice outcomes and leverage susceptibility to adversity. Exploring the concept of personal resilience among IENs in future research in order to uncover its different dimensions is vital for more decisive conclusions on IEN resilience.

\section{References}

1. Canadian Institute for Health Information (CIHI) (2010) Regulated Nurses: Canadian Trends, 2006 to 2010.

2. Health Canada (2004) Health human resources: Balancing supply and demand. Health policy research bulletin.

3. O’Brien-Pallas L, Alksnis C, Wang S, Birch S, Tomblin Murphy G, et al. (2003) Early retirement among RNs: Estimating the Size of the Problem in Canada. Hospital Quarterly 7 (1): 1-8.

4. Baumann A, Idriss W (2012) The big picture: Immigration and labor market trends. Presented at the Path to Integration: A workshop for Employers of Internationally Educated Nurses. Canada.

5. Jose MM (2011) Lived experiences of internationally educated nurses in hospitals in the United States of America. Int Nurs Rev 58(1): 123129.

6. Kawi J, Xu Y (2009) Facilitators and barriers to adjustment of international nurses: An integrative review. Int Nurs Rev 56(2): 174183.

7. Magnusdottir H (2005) Overcoming strangeness and communication barriers: A phenomenological study of becoming a foreign nurse. Int Nurs Rev 52(4): 263-269.

8. Jackson D, Firtko A, Edenborough M (2007) Personal resilience as a strategy for surviving and thriving in the face of workplace adversity: a literature review. J Adv Nurs 60 (1): 1-9.

9. Husserl E (1913) The crisis of European sciences and transcendental phenomenology (D. Carr, Trans.). Northwestern University Press, Evanston, USA.

10. Morse J (1995) Defining comfort for the improvement of nursing care. Qualitative Research Methods for Health Professionals. pp. 162-193.

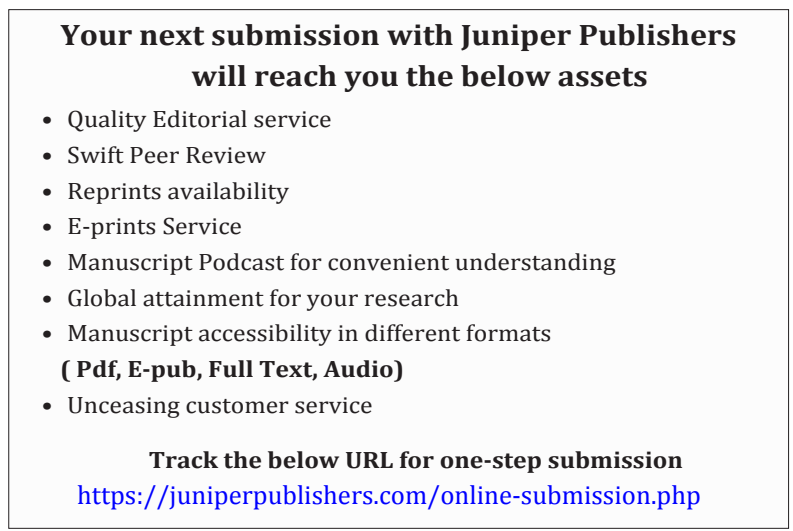

